\title{
Characterisation of inhalable atmospheric aerosols
}

\author{
N. A. Kgabi ${ }^{1}$, J. J. Pienaar $^{2} \&$ M. Kulmala ${ }^{3}$ \\ ${ }^{I}$ Department of Physics, North-West University, Mmabatho, South Africa \\ ${ }^{2}$ School of Chemistry, North-West University, Potchefstroom, \\ South Africa \\ ${ }^{3}$ Department of Physical Sciences, University of Helsinki, P. O. BOX 64, \\ FIN-00014, Helsinki, Finland
}

\begin{abstract}
A better understanding of the chemical constituents of ambient particles is fundamental in bridging the knowledge gap between the air quality and its health effects. In this study, Inductively Coupled Plasma Mass Spectroscopy (ICP-MS), Atomic Absorption Spectrometry (AAS) and Scanning Electron Microscopy coupled with Energy Dispersive Spectrometry (SEM/EDS) were used to characterise the inhalable atmospheric particulate matter (PM10). About 30 elements were identified using ICP-MS and the mean concentrations of $\mathrm{Cr}, \mathrm{Ni}, \mathrm{V}$ and $\mathrm{Pb}$ for the sites RMINE and RCBD were found to be $2.55( \pm 1.42)$ and $0.18( \pm 0.08), 1.41( \pm 0.73)$ and $0.13( \pm 0.07), 0.28( \pm 0.12)$ and $0.03( \pm 0.01)$, and $0.35( \pm 0.15)$ and $0.48( \pm 0.28) \mu \mathrm{g} / \mathrm{m}^{3}$ respectively. SEM/EDS yielded information on most crustal elements and their total oxides but could not detect $\mathrm{Ni}, \mathrm{V}$ and $\mathrm{Pb}$. The $\mathrm{Cr}$ concentrations at the two sites in the Rustenburg municipality were measured as $2.28( \pm 0.64)$ and $0.14( \pm 0.04) \mu \mathrm{g} / \mathrm{m}^{3}$. AAS yielded the toxic metal concentrations of $1.03( \pm 0.54)$ and $1.52( \pm 0.56)$ for $\mathrm{Cr}, 0.29( \pm 0.09)$ and $0.58( \pm 0.23)$ for $\mathrm{Ni}, 1.37( \pm 1.02)$ and $1.38( \pm 0.59)$ for $\mathrm{V}$, and $1.32( \pm 0.27)$ and $1.31( \pm 0.57) \mu \mathrm{g} / \mathrm{m}^{3}$ for $\mathrm{Pb}$. All the methods used could not give unambiguous information on specific oxides of metals.
\end{abstract}

Keywords: particulate matter, ICP-MS, SEM/EDS, AAS. 


\section{Introduction}

Characterisation of inhalable airborne particulates is becoming increasingly important to governments, regulators and researchers due to their potential impacts on human health [1], transnational migration and influence on climate forcing and global warming [2] and on the ecosystems [3]. Chemical speciation is essential for establishing more specific relationships between particle concentrations and measures of public health. Monitoring of both PM mass and chemical composition is also important for identification of emission sources, determination of compliance, and development of effective control programs.

Major components of atmospheric aerosols include sulphate, nitrate, ammonium, and hydrogen ions; trace elements (including toxic and transition metals); organic material; elemental carbon (or soot); and crustal components [4]. Each aerosol species is formed in the atmosphere separately by different processes and are mixed together to form particles of mixed composition.

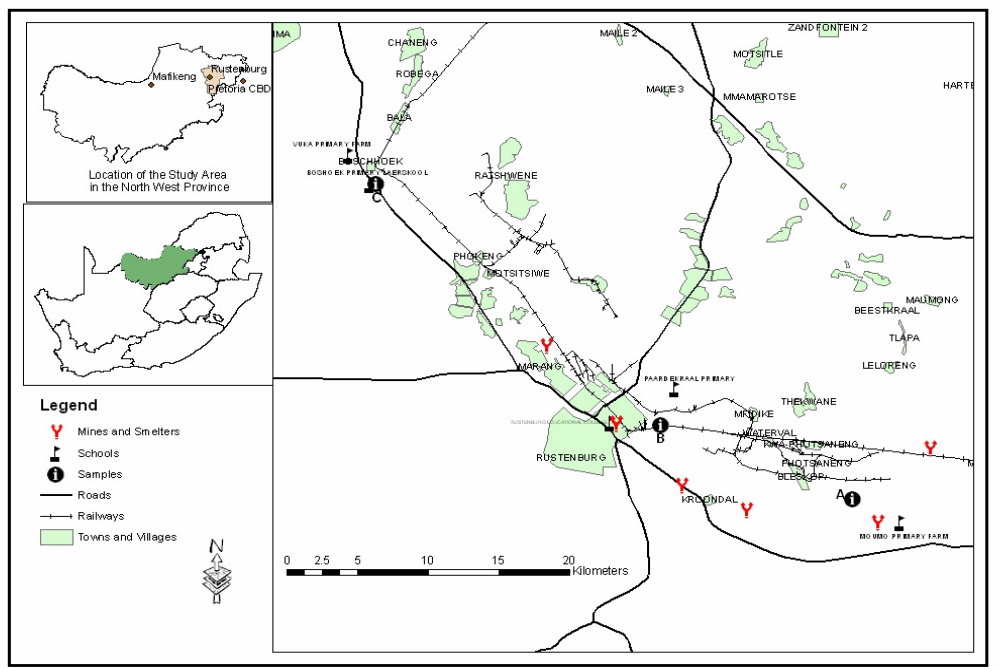

Figure 1: A map showing the location of the study sites RMINE and RCBD given as A and B respectively, in the Rustenburg municipality.

Insoluble aerosols act as foreign bodies stimulating defence reactions in living organisms, e.g. crystalline silica (quartz) relative toxic to cells. Soluble aerosols are easily transferred to blood and other parts of the body, e.g. lead, cadmium. The molecular form (e.g. oxidation state) is very important in metal-containing aerosols [5].

The sampling of the atmospheric particulate aerosols was performed using the TEOM series 1400a incorporated with the $\mathrm{PM}_{10}$ inlet at two sites $\mathrm{A}$, hereafter referred to as RMINE with latitude $25^{\circ} 43^{\prime} 03,0^{\prime \prime} \mathrm{E}$ and longitude 
$27^{\circ} 23^{\prime} 57,8^{\prime \prime} \mathrm{S}$, and $\mathrm{B}$, which is referred to as RCBD with latitude $25^{\circ} 40^{\prime} 01,3^{\prime \prime} \mathrm{E}$ and longitude $27^{\circ} 16^{\prime} 38,5^{\prime \prime} \mathrm{S}$. These sites are representative of well-defined environments, exposure situations or source activities like remote areas, urban background, traffic, and industry. The map in Figure 1 shows the location of RMINE and RCBD.

The objective of this study was to determine the composition of the inhalable particulate aerosols and hence evaluate the efficiency of the Inductively Coupled Plasma Mass Spectroscopy (ICP-MS), Atomic Absorption Spectrometry (AAS) and Scanning Electron Microscopy coupled with Energy Dispersive Spectrometry (SEM/EDS).

\section{Experimental}

The ambient air samples used for ICP-MS, SEM/EDS and AAS analysis were collected on $15 \mathrm{~mm}$ Teflon Coated Borosilicate glass fibre filters at the flow rate of $3.0 \mathrm{~L} / \mathrm{min}$ with the total flow of $16.7 \mathrm{~L} / \mathrm{min}$ where the $13.7 \mathrm{~L} / \mathrm{min}$ was the bypass flow. The filters were changed monthly, or when they are approximately $80 \%$ full, using the forceps and placed in the plastic containers with caps. The filters were scanned using SEM/EDS, followed by extraction for ICP-MS. A portion of the extracted solution from ICP-MS was stored for further analysis using AAS. Thus each sample was analysed using the three methods.

The ESEM FEI QUANTA 200 coupled with the OXFID ENCA 200 EDS was used for elemental analysis of samples. The requirements for sample analysis by SEM are that the sample has to be stable under the vacuum conditions, it has to be conductive to allow electron beam irradiation, and lastly the substrate of sample should fit well into the sample stage. The samples were analysed at high vacuum, with a voltage of $15 \mathrm{kV}$ and the working distance of $10 \mathrm{~mm}$. A dead time of forty percent, which corresponds to the live time of 100 seconds, was used during the analysis of samples. The filters were fixed onto sample studs to ensure good electrical connection between the specimen and the microscope stage. The samples were not coated. The filters were scanned several (10) times (1 scan per 10 second) to ensure that the representative portion of the sample is covered. No extraction was performed.

The samples collected on filters were also analysed using the Agilent ICP-MS $7500 \mathrm{c}$ with the operating conditions and measurement parameters given as 3 replicates, Rf power of $1.6 \mathrm{~kW}$, Rf Matching of $1.64 \mathrm{~V}$, carrier gas flow rate of $1.09 \mathrm{~L} / \mathrm{min}$, wash time and rinse time of $5 \mathrm{~s}$ and $60 \mathrm{~s}$ respectively, sample uptake rate and stabilization of $55 \mathrm{~s}$ and $45 \mathrm{~s}$ respectively. Air particulates collected on filters were extracted into a dilute nitric acid solution by sonication with heating and the extracted solution was stored at room temperature until analysis by ICPMS.

AAS is the quantitative technique in which the optical absorption of atoms in the ground state is measured when the sample is irradiated with the appropriate source that is; the absorption of optical radiation by atoms in the gaseous state is measured. The elemental analysis depends on the measurements made on the analyte (solution) that is transformed into free atoms. 
A limitation associated with the ICP-MS and AAS analysis is the difficulty in assessing the efficiency of extracting the PM from different filters. This has been reported before by researchers who estimated an efficiency of $20-50 \%$ of PM removed from filters [6] and those who estimated an efficiency of 10-30\% [7]. Attempts were made to assess the extraction efficiency by measuring the extracted mass. The other limiting factor in these procedures may be the possibility of contamination as the extraction solution for ICP-MS was further treated and used for AAS analysis.

\section{Discussion of results}

The chemical composition of samples that were compared was collected at the sites described in section 2. Sample 1, 2 and 3 were obtained at RMINE during the sampling periods 20 February - 12 March 2004, 22 April - 15 May 2004 and 15 May - 8 June 2004 respectively, and Sample 4, 5, 6, 7, 8, 9, 10 and 11 were collected at RCBD during the periods 8 - 29 June 2004, 29 June - 23 July 2004, 23 July - 19 August 2004, 19 August - 10 September 2004, 10 - 28 September 2004, 28 September - 26 October 2004, 26 October - 12 November 2004 and 12 - 23 November 2004 respectively. The composition of these samples was determined using SEM/EDS, ICP-MS and AAS.

\subsection{SEM/EDS}

Figure 2 gives the morphology of Sample 1. The dark area indicates the carbon content, the greyish area is mainly the silica and the white areas are the $\mathrm{Cr}$ content [8]. Greyish particles are predominantly geological elements that include the iron, silica and manganese. This can be attributed to re-suspension of soil particles during wind episodes and emissions from the industry during mineral processing. Angular fractured grains are produced as a result of mining and milling processes. The irregularly shaped particles may be linked to the results of anthropogenic abrading processes. The white particles that are predominantly chromium and its oxides can be associated with the industrial

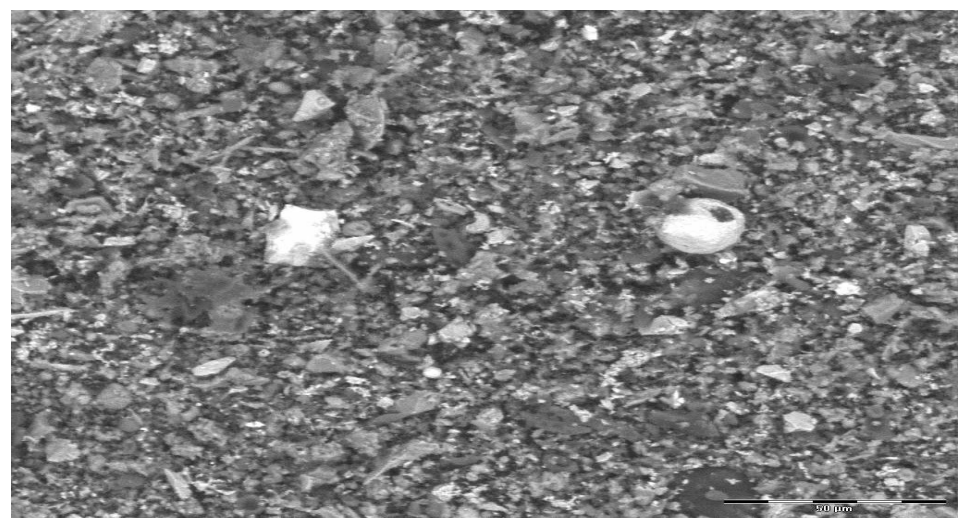

Figure 2: $\quad$ Micrograph of Sample 1 obtained at RMINE. 
emissions particularly the ferrochrome smelter located about $15 \mathrm{~km}$ from the study area.

Spherical particles shown in Figure 2 are typically associated with particles that have been formed in a high-temperature furnace, such as a coal-fired boiler. These are typically alumino-silicates, often with significant concentrations of iron that come from pyrites and other iron-containing minerals in coal [9]. Smelting operations may also generate spherical particles, including elements specific to the ores. This simply means that the ferrochrome smelter in the study area is expected to emit $\mathrm{Cr}$ and $\mathrm{Fe}$ that are predominantly spherical in shape. Elemental analysis indicates that a large portion of the spherical particles contain elevated concentrations of carbon, oxygen, and silicon and lesser quantities of magnesium, sodium, aluminium, sulphur, calcium, and silicon.

Table 1 gives the concentrations of the oxides of the elements identified at RMINE. For all the samples described above, the data was obtained from analysis of Teflon-coated borosilicate fibreglass filters.

Table 1: $\quad$ Concentrations (in $\mu \mathrm{gm}^{-3}$ ) of oxides of the elements identified by using SEM/EDS during autumn and winter at RMINE.

\begin{tabular}{|lccccccccccccccc|}
\hline Sample & PM10 & $\mathbf{S i}$ & Fe & Al & Ca & Mg & K & Na & Ti & Cr & C & Cl & S & F & O \\
\hline 1 & 131.10 & 7.08 & 3.28 & 4.06 & 1.44 & 1.70 & 0.52 & 1.05 & 0.40 & 3.28 & 18.22 & - & 6.42 & 8.39 & 74.73 \\
2 & 99.74 & 14.16 & 3.49 & 5.69 & 3.59 & 3.29 & 0.60 & 0.70 & - & 1.10 & 8.08 & 0.30 & 4.29 & - & 54.66 \\
3 & 94.36 & 14.44 & 5.57 & 5.76 & 3.96 & 3.02 & 0.57 & 0.57 & 0.28 & 2.45 & 6.89 & 0.28 & 1.60 & - & 45.39 \\
MEAN & $\mathbf{1 0 8 . 4}$ & $\mathbf{1 1 . 8 9}$ & $\mathbf{4 . 1 1}$ & $\mathbf{5 . 1 7}$ & $\mathbf{3 . 0 0}$ & $\mathbf{2 . 6 7}$ & $\mathbf{0 . 5 6}$ & $\mathbf{0 . 7 7}$ & $\mathbf{0 . 2 3}$ & $\mathbf{2 . 2 8}$ & $\mathbf{1 1 . 0 6}$ & $\mathbf{0 . 1 9}$ & $\mathbf{4 . 1 0}$ & $\mathbf{2 . 8 0}$ & $\mathbf{5 8 . 2 6}$ \\
SD & $\mathbf{1 1 . 4 6}$ & $\mathbf{2 . 4 1}$ & $\mathbf{0 . 7 3}$ & $\mathbf{0 . 5 6}$ & $\mathbf{0 . 7 9}$ & $\mathbf{0 . 4 9}$ & $\mathbf{0 . 0 2}$ & $\mathbf{0 . 1 4}$ & $\mathbf{0 . 1 2}$ & $\mathbf{0 . 6 4}$ & $\mathbf{3 . 5 9}$ & $\mathbf{0 . 1 0}$ & $\mathbf{1 . 3 9}$ & $\mathbf{2 . 8 0}$ & $\mathbf{8 . 6 6}$ \\
\hline
\end{tabular}

The oxides on the main elements identified at this site are $\mathrm{Si}, \mathrm{Fe}, \mathrm{Al}, \mathrm{Ca}, \mathrm{Mg}$, $\mathrm{K}, \mathrm{Na}, \mathrm{Ti}, \mathrm{Cr}, \mathrm{C}, \mathrm{Cl}, \mathrm{S}, \mathrm{F}$ and $\mathrm{O}$. There is an increase in concentrations of crustal elements $\mathrm{Si}, \mathrm{Fe}, \mathrm{Al}, \mathrm{Ca}, \mathrm{Na}$ and $\mathrm{Mg}$ from the autumn to the winter season. The $\mathrm{S}$ and $\mathrm{C}$ concentrations also show a decrease from autumn to winter. South Africa has dry winter seasons and the concentration of $S$ shown in Table 1, at the beginning of winter (15 May to 8 June) is $1.60 \mu \mathrm{gm}^{-3}, 4.29 \mu \mathrm{gm}^{-3}$ (22 April to 15

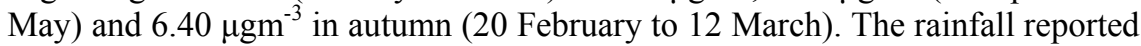
by the South African Weather Services as given in Table 2 are 175.6, 11, 27.4, 0.2 , and $5.2 \mathrm{~mm}$ for the months of February, March, April, May and June respectively. The levels of the oxides of sulphur are very important in a study that deals with toxic trace metals, because most of the metals occur in ambient air as sulphates.

The potentially toxic metal of interest identified at RMINE is Cr, with concentrations of $3.28,1.10$, and $2.45 \mu \mathrm{g} . \mathrm{m}^{-3}$ for the three samples analysed at this site. This has serious implications since for Sample 1 and 3; the limit of 1.5 $\mu \mathrm{g} . \mathrm{m}^{-3}$ for $\mathrm{Cr}$, set by the Asia Pacific Centre for Environmental Law (APCEL) is exceeded [10]. The limit of $1000 \mathrm{ng} / \mathrm{m}^{3}\left(1 \mu \mathrm{g} \cdot \mathrm{m}^{-3}\right)$ set by the National Institute for Occupational Safety and Health (NIOSH) was exceeded for the whole sampling period at this site. 
The elements identified at RCBD, as shown in Table 2 include $\mathrm{Si}, \mathrm{Fe}, \mathrm{Al}, \mathrm{Ca}$, $\mathrm{Mg}, \mathrm{K}, \mathrm{Na}, \mathrm{Ti}, \mathrm{Cr}, \mathrm{C}, \mathrm{Cl}, \mathrm{S}, \mathrm{F}, \mathrm{V}, \mathrm{Pb}$, and N. For most samples, the oxides of Pb, $\mathrm{V}, \mathrm{N}, \mathrm{P}$ and $\mathrm{F}$ could not be detected.

Table 2: $\quad$ Concentrations (in $\mu \mathrm{gm}^{-3}$ ) of oxides of the elements identified by using SEM/EDS during winter, spring and summer at RCBD.

\begin{tabular}{|lllllllllllllllllll}
\hline Sample PM10 Si & $\mathbf{F e}$ & $\mathbf{A l}$ & $\mathbf{C a}$ & $\mathbf{M g}$ & $\mathbf{K}$ & $\mathbf{N a}$ & $\mathbf{T i}$ & $\mathbf{C r}$ & $\mathbf{C}$ & $\mathbf{C l}$ & $\mathbf{S}$ & $\mathbf{F}$ & $\mathbf{P}$ & $\mathbf{V}$ & $\mathbf{P b}$ & $\mathbf{O}$ & \\
\hline 4 & 48.73 & 1.41 & - & 0.68 & 0.15 & 0.39 & 0.19 & 0.24 & - & - & 11.26 & 0.10 & 0.68 & - & - & - & - \\
5 & 49.28 & 2.12 & 0.30 & 0.99 & 0.25 & 0.39 & 0.35 & 0.15 & - & 0.10 & 10.50 & 0.10 & 0.84 & - & 0.05 & - & - & 33.67 \\
6 & 48.39 & 2.41 & 0.19 & 0.77 & 0.24 & 0.34 & 0.44 & 0.34 & 0.05 & - & 9.19 & 0.10 & 0.44 & 4.65 & - & - & - & 29.28 \\
7 & 47.10 & 3.96 & 1.27 & - & 0.61 & 0.57 & 0.47 & 0.33 & 0.09 & 0.28 & 7.58 & 0.19 & 0.99 & - & 0.09 & - & - & 29.11 \\
8 & 45.51 & 2.78 & 0.68 & 1.18 & 0.41 & 0.41 & 0.46 & 0.36 & 0.05 & 0.14 & 8.33 & 0.09 & 0.68 & 1.55 & - & - & - & 28.35 \\
9 & 44.22 & 2.39 & 0.62 & 0.97 & 0.31 & 0.4 & 0.35 & 0.27 & - & 0.13 & 7.03 & - & 1.81 & - & - & - & - & 28.88 \\
10 & 43.06 & 2.50 & 0.60 & 0.99 & 0.34 & 0.56 & 0.26 & 0.34 & - & 0.17 & 8.01 & 0.13 & 1.25 & - & - & - & - & 27.90 \\
11 & 46.46 & 3.58 & 1.02 & 1.49 & 0.37 & 0.51 & 0.23 & 0.23 & 0.09 & 0.28 & 7.43 & - & 1.81 & - & - & 0.02 & 0.24 & 29.08 \\
$\mathbf{M E A N}$ & $\mathbf{4 6 . 5 2}$ & $\mathbf{2 . 6 4}$ & $\mathbf{0 . 5 9}$ & $\mathbf{0 . 8 8}$ & $\mathbf{0 . 3 4}$ & $\mathbf{0 . 4 5}$ & $\mathbf{0 . 3 4}$ & $\mathbf{0 . 2 8}$ & $\mathbf{0 . 0 4}$ & $\mathbf{0 . 1 4}$ & $\mathbf{8 . 6 7}$ & $\mathbf{0 . 0 9}$ & $\mathbf{1 . 0 6}$ & $\mathbf{0 . 7 8}$ & $\mathbf{0 . 0 2}$ & $\mathbf{0 . 0 0}$ & $\mathbf{0 . 0 3}$ & $\mathbf{2 9 . 9 3}$ \\
$\mathbf{S D}$ & $\mathbf{0 . 9 0}$ & $\mathbf{0 . 2 9}$ & $\mathbf{0 . 1 5}$ & $\mathbf{0 . 1 5}$ & $\mathbf{0 . 0 5}$ & $\mathbf{0 . 0 3}$ & $\mathbf{0 . 0 4}$ & $\mathbf{0 . 0 3}$ & $\mathbf{0 . 0 1}$ & $\mathbf{0 . 0 4}$ & $\mathbf{0 . 5 4}$ & $\mathbf{0 . 0 2}$ & $\mathbf{0 . 1 8}$ & $\mathbf{0 . 5 9}$ & $\mathbf{0 . 0 1}$ & $\mathbf{0 . 0 0}$ & $\mathbf{0 . 0 3}$ & $\mathbf{0 . 7 8}$ \\
\hline
\end{tabular}

The oxides linked with $\mathrm{Cl}$ were identified in almost all samples and $\mathrm{P}$ was identified in the winter (June - July) and Spring (August - September) samples. The occurence of oxides of $\mathrm{P}, \mathrm{Cl}$ at $\mathrm{RCBD}$ may suggest the presence of $\mathrm{a} \mathrm{Pb}$ phosphate mineral ( $\mathrm{Pb}-\mathrm{P}-\mathrm{Ca}$ and/or $\mathrm{Cl})$ in the samples [5].

The concentrations of $\mathrm{S}$ identified in this study ranged from 0.44 to 1.81 $\mu \mathrm{g} . \mathrm{m}^{-3}$. Sulphur-bearing particles are very common in ambient PM samples. They are found in virtually all airborne PM samples [11-13].

The potentially toxic trace metals identified in the samples include $\mathrm{Cr}, \mathrm{V}$ and $\mathrm{Pb}$, though $\mathrm{V}$ and $\mathrm{Pb}$ were only be identified the samples collected in summer. This could not be explained since it can be expected that the levels of $\mathrm{Cr}, \mathrm{V}$, and $\mathrm{Pb}$ are related mainly to mining and/or industrial activities and not meteorology. There is no clear trend in the levels of $\mathrm{Cr}$ within the study site. The levels ranged from 0.10 to $0.28 \mu \mathrm{g} \cdot \mathrm{m}^{-3}$ for $\mathrm{Cr}$, and the concentrations of $\mathrm{Pb}$ and $\mathrm{V}$ were measured as 0.24 and $0.02 \mu \mathrm{g} . \mathrm{m}^{-3}$ respectively.

\subsection{ICP-MS}

Table 3 shows the metals identified using ICP-MS and their concentration levels. About 15 main metals were identified. The crustal elements identified included $\mathrm{Si}, \mathrm{Fe}, \mathrm{Al}, \mathrm{Ca}, \mathrm{Mg}, \mathrm{K}, \mathrm{Na}, \mathrm{Ti}$, and toxic trace elements identified are $\mathrm{Cr}, \mathrm{Ni}, \mathrm{V}$, $\mathrm{Pb}, \mathrm{Cu}, \mathrm{Zn}$, and $\mathrm{Mn}$.

There are no clear relations between the toxic trace metal concentrations $(\mathrm{Cr}$, $\mathrm{Ni}, \mathrm{V}, \mathrm{Pb}, \mathrm{Cu}, \mathrm{Zn}$, and $\mathrm{Mn}$ ) and the seasons or months of the year. $\mathrm{K}$ increases from autumn to winter and crustal elements $\mathrm{Ti}, \mathrm{Fe}, \mathrm{Ca}$ decrease from autumn to winter. This may be because of the increase in biomass burning during winter since $\mathrm{K}$ is a tracer for biomass burning. 
Table 3: Concentrations (in $\mu \mathrm{g} \cdot \mathrm{m}^{-3}$ ) of the elements identified using ICPMS during autumn and winter at RMINE.

\begin{tabular}{|c|c|c|c|c|c|c|c|c|c|c|c|c|c|c|c|c|}
\hline Sample & PM10 & $\mathbf{S i}$ & $\mathrm{Fe}$ & Al & $\mathrm{Ca}$ & Mg & $\mathbf{K}$ & $\mathrm{Na}$ & $\mathbf{T i}$ & $\mathrm{Cr}$ & $\mathbf{N i}$ & V & $\mathbf{P b}$ & $\mathrm{Cu}$ & $\mathrm{Zn}$ & Mn \\
\hline \multicolumn{17}{|l|}{1} \\
\hline \multirow[b]{2}{*}{2} & 131.10 & 2.12 & 25.00 & 4.43 & 7.52 & 3.08 & 0.46 & 1.44 & 0.32 & 2.10 & 1.10 & 0.40 & 0.50 & 0.19 & 0.38 & 0.21 \\
\hline & 99.74 & 2.50 & 8.48 & 5.20 & 5.30 & 3.56 & 0.54 & 2.02 & 0.12 & 0.36 & 0.34 & 0.04 & 0.06 & 0.26 & 0.38 & 25.00 \\
\hline 3 & 94.36 & 1.54 & 5.02 & 1.92 & 1.92 & 1.54 & 0.57 & 1.40 & 0.08 & 5.20 & 2.80 & 0.40 & 0.50 & 0.21 & 0.26 & 0.21 \\
\hline \multicolumn{17}{|l|}{ Mean } \\
\hline \multirow[b]{2}{*}{ SD } & 108.40 & 2.05 & 12.83 & 3.85 & 4.91 & 2.73 & 0.52 & 1.62 & 0.17 & 2.55 & 1.41 & 0.28 & 0.35 & 0.22 & 0.34 & 8.47 \\
\hline & 11.46 & 0.28 & 6.16 & 0.99 & 1.63 & 0.61 & 0.03 & 0.20 & 0.07 & 1.42 & 0.73 & 0.12 & 0.15 & 0.02 & 0.04 & 8.26 \\
\hline
\end{tabular}

It is worth noting that the different techniques used in this study show different sensitivities to different metals thus, the elements that could not be identified using SEM/EDS are Ti, $\mathrm{Cu}, \mathrm{Zn}$, and $\mathrm{Mn}$. The levels of $\mathrm{Mn}$ are very high for Sample 2 and this could not be explained. It can however be an analysis error associated with the technique because the value is of three orders of magnitude higher than Sample 1 and 3 and thus clearly out of acceptable range. The $\mathrm{Zn}$ and $\mathrm{Cu}$ identified have concentration range of 0.26 to $0.36 \mu \mathrm{g} \cdot \mathrm{m}^{-3}$ and 0.19 to 0.26 respectively. Table 4 shows the average monthly concentrations determined at RCBD during the study.

Table 4: Concentrations (in $\mu \mathrm{g} \cdot \mathrm{m}^{-3}$ ) of elements identified by ICP-MS during winter, spring and summer at RCBD.

\begin{tabular}{|c|c|c|c|c|c|c|c|c|c|c|c|c|c|c|c|c|}
\hline Sample & PM10 & $\mathbf{S i}$ & $\mathrm{Fe}$ & Al & $\mathrm{Ca}$ & Mg & $\mathbf{K}$ & $\mathbf{N a}$ & $\mathbf{T i}$ & $\mathrm{Cr}$ & $\mathrm{Ni}$ & $\mathbf{V}$ & $\mathbf{P b}$ & $\mathrm{Cu}$ & $\mathrm{Zn}$ & Mn \\
\hline \multicolumn{17}{|l|}{4} \\
\hline & 48.73 & 10.20 & 0.20 & 3.10 & 2.30 & 3.20 & 2.30 & 3.10 & 0.01 & 0.02 & 0.00 & 0.05 & 0.00 & 0.08 & 0.10 & 0.40 \\
\hline 5 & 49.28 & 1.60 & 5.20 & 2.00 & 2.00 & 1.60 & 0.60 & 1.50 & 0.80 & 0.50 & 0.30 & 0.04 & 0.05 & 0.20 & 0.30 & 0.20 \\
\hline 6 & 48.39 & 9.10 & 10.70 & 1.90 & 3.20 & 1.30 & 0.20 & 0.60 & 0.10 & 0.09 & 0.05 & 0.02 & 0.02 & 0.08 & 0.17 & 0.09 \\
\hline 8 & 45.51 & 3.30 & 11.30 & 6.90 & 7.10 & 4.8 & 0.70 & 2.70 & 0.17 & 0.50 & 0.46 & 0.05 & 0.08 & 0.35 & 0.50 & 0.33 \\
\hline 9 & 44.22 & 0.20 & 8.50 & 3.10 & 3.70 & 2.70 & 2.20 & 2.90 & 0.07 & 0.05 & 0.03 & 0.02 & 1.40 & 0.02 & 0.35 & 0.51 \\
\hline 10 & 43.06 & 0.93 & 10.00 & 4.20 & 3.70 & 3.60 & 1.80 & 4.40 & 0.07 & 0.06 & 0.05 & 0.04 & 1.70 & 0.03 & 0.49 & 0.62 \\
\hline 11 & 46.46 & - & 0.93 & 3.00 & 1.70 & 1.40 & 0.41 & 0.82 & 0.09 & 0.03 & 0.03 & 0.01 & 0.10 & 0.61 & 0.40 & 0.04 \\
\hline Mean & 46.52 & 4.22 & 6.69 & 3.46 & 3.39 & 2.66 & 1.17 & 2.29 & 0.19 & 0.18 & 0.13 & 0.03 & 0.48 & 0.20 & 0.33 & 0.31 \\
\hline SD & 0.90 & 1.77 & 1.75 & 0.64 & 0.69 & 0.50 & 0.34 & 0.52 & 0.10 & 0.08 & 0.07 & 0.01 & 0.28 & 0.08 & 0.06 & 0.08 \\
\hline
\end{tabular}

There seem to be no clear trends for most of the elements identified except for a trend observed during spring for $\mathrm{Na}, \mathrm{Pb}, \mathrm{Mn}$ and $\mathrm{K}$ in Sample 6, 8 and 9. These show an increase in concentration as temperature increases as shown in Table 5, where the temperatures $23.8,25.7$ and $28.8{ }^{\circ} \mathrm{C}$ were measured for the months of August, September and October respectively. 
Table 5: Monthly meteorological data for the Rustenburg area supplied by the South African Weather Services (SAWS) [14].

\begin{tabular}{|c|c|c|c|c|c|c|}
\hline \multirow[t]{2}{*}{ Season } & \multirow[t]{2}{*}{ Month } & \multicolumn{2}{|c|}{$\begin{array}{l}\text { Temperature } \\
\left({ }^{\circ} \mathrm{C}\right)\end{array}$} & \multirow[t]{2}{*}{$\begin{array}{l}\text { Rainfall } \\
\text { (ml) }\end{array}$} & \multirow{2}{*}{$\begin{array}{l}\text { Wind } \\
\text { Speed } \\
(\mathbf{m} / \mathbf{s})\end{array}$} & \multirow{2}{*}{$\begin{array}{l}\text { Wind Direction } \\
\text { (Degrees from } \\
\text { true North) }\end{array}$} \\
\hline & & Min & $\operatorname{Max}$ & & & \\
\hline \multirow[t]{2}{*}{ Autumn } & Mar -04 & 14.7 & 25.9 & 11.0 & 15.5 & 347 (NNW) \\
\hline & Apr -04 & 12.4 & 25.4 & 27.4 & 16.3 & $337(\mathrm{NNW})$ \\
\hline \multirow[t]{3}{*}{ Winter } & May -04 & 7.0 & 24.3 & 0.2 & 8.7 & 337 (NNW) \\
\hline & Jun -04 & 2.7 & 19.4 & 5.2 & 12.2 & 354 (NNW) \\
\hline & Jul -04 & 1.0 & 19.6 & 0.0 & 13.3 & $349(\mathrm{~N})$ \\
\hline \multirow[t]{3}{*}{ Spring } & Aug -04 & 6.5 & 23.8 & 1.6 & 15.7 & $349(\mathrm{~N})$ \\
\hline & Sep -04 & 7.5 & 25.7 & 0.2 & 16.7 & 340 (NNW) \\
\hline & Oct -04 & 12.5 & 28.8 & 39.4 & 9.4 & $176(\mathrm{~S})$ \\
\hline \multirow[t]{3}{*}{ Summer } & Nov -04 & 15.3 & 31.5 & 38.2 & 10.2 & 165 (SSE) \\
\hline & Dec -04 & 16.0 & 29.2 & 83 & 10.4 & 163 (SSE) \\
\hline & Jan -05 & 17.4 & 29.4 & 160 & 9.0 & 204 (SSW) \\
\hline \multirow[t]{3}{*}{ Autumn } & Feb -05 & 16.5 & 29.7 & 78.6 & 8.5 & 161 (SSE) \\
\hline & Mar - 05 & 14.1 & 27.3 & 42.4 & 8.8 & $190(\mathrm{~S})$ \\
\hline & Apr -05 & 11.5 & 23.2 & 91 & 7.3 & $196(\mathrm{SSW})$ \\
\hline \multirow[t]{3}{*}{ Winter } & May - 05 & 6.4 & 23.5 & 0.8 & 6.7 & $188(\mathrm{~S})$ \\
\hline & Jun -05 & 4.4 & 22.6 & 0.0 & 6.8 & 205 (SSW) \\
\hline & Jul - 05 & 2.8 & 22.0 & 0.0 & 6.0 & 164 (SSE) \\
\hline
\end{tabular}

The peak in the $\mathrm{K}$ concentrations for Sample 4 and 9 may indicate activities related to biomass burning. This can be expected during winter (Sample 4) since there are more forest fires during this season. The peak in spring (Sample 9) may also indicate the effect of forest fires but from regional pollution, since the spring season is characterised by high wind speeds of $15.7 \mathrm{~m} . \mathrm{s}^{-1}$ in August, $16.7 \mathrm{~m} . \mathrm{s}^{-1}$ in September and $9.4 \mathrm{~m} . \mathrm{s}^{-1}$ in October 2004 (shown in Table 5) blowing from regions known for biomass burning.

The $\mathrm{Cr}$ and Ni concentrations are lowest for Sample 4 and 11. This could not be explained since the wind directions corresponding to the samples are oppositely directed, that is, NNW in June and SSE in November 2004, and the temperatures are also varied i.e. 19.4 and $31.5^{\circ} \mathrm{C}$ for June and November respectively. The wind speeds are however, roughly the same (12.2 and $10.2 \mathrm{~m} . \mathrm{s}^{-1}$ ) for June and November. The levels of $\mathrm{Ca}, \mathrm{Mn}$ and $\mathrm{V}$ are also lowest for Sample 11.

The $\mathrm{Pb}$ concentrations show a maximum for Sample $9\left(1.4 \mu \mathrm{g} . \mathrm{m}^{-3}\right)$ and 10 (and $1.7 \mu \mathrm{g} . \mathrm{m}^{-3}$ ). The wind speeds for Sample 9 and 10 are lower $(9.4$ and 10.2 $\mathrm{m} . \mathrm{s}^{-1}$ for October and November) than for the samples obtained between June and September, which rules out the possibility of contribution from soil dust. The wind direction ( $\mathrm{S}$ and $\mathrm{SSE}$ ) corresponding to these samples can be responsible for the $\mathrm{Pb}$ levels, since they imply that the wind was blowing from the central business district, where there are more activities related to traffic.

\subsection{AAS}

The AAS analysis was performed to determine only $\mathrm{Cr}, \mathrm{Ni}, \mathrm{V}$ and $\mathrm{Pb}$ since these were the only elements for which the lamps were available. The results discussed in this section therefore only covers the four trace metals. Figure 3 gives the concentrations of these elements for Sample 1 to 7. 


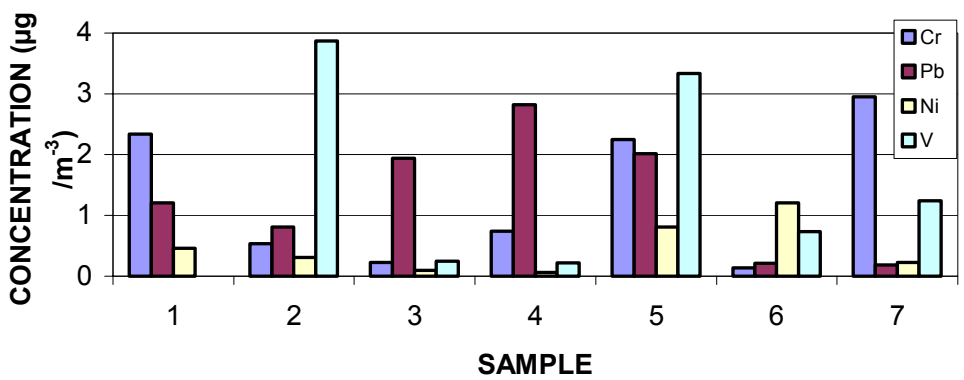

Figure 3: Concentrations of trace metals at RMINE (1, 2 and 3) and RCBD $(4,5,6$ and 7$)$.

Chromium (Cr) and Nickel (Ni) concentrations decrease as the season changes from autumn to winter. This is probably because of the decrease in temperature, since it is warmer in autumn than in winter. It is documented that the winter nocturnal surface inversion has a depth of $400-600 \mathrm{~m}$ and strength of $5-7{ }^{0} \mathrm{C}$ over southern Africa as a whole [15]. This implies that the pollution released into a stable inversion layer is seldom able to rise through it and disperses slowly in clearly defined plumes.

The metal concentrations of $\mathrm{Cr}$ and $\mathrm{Ni}$ decrease from Sample 1 to 3, this is surprising since it was expected that concentrations should be higher in Sample 3 collected during winter than Sample 1 during autumn, because during winter the community burn coal and woods as a source of fuel for heating and cooking. This however, may suggest the source of high metal concentrations to be the industrial activities and not domestic and natural activities. The large variations in concentrations and differences in the ratio between the metals are indicative of the diversity of emission sources at this site.

The average concentration of $\mathrm{Pb}$ obtained from data over a 3 month period at RMINE is $1,32 \mu \mathrm{g} . \mathrm{m}^{-3}$ and this value is above the 3 months average value of $0.20 \mu \mathrm{g} . \mathrm{m}^{-3}$ set by Ministry for the Environment and the Ministry of Health (ME and $\mathrm{MH}$ ) [16].

$\mathrm{The} \mathrm{Pb}$ concentration decreases from winter to spring at RCBD. This may be due to the fact that, $\mathrm{Pb}$ may occur in the atmosphere in the form of Lead sulphate, Lead carbonate and Lead-phosphate; and AAS cannot successfully measure the total carbon in particulate matter.

The levels of $\mathrm{Cr}, \mathrm{Ni}, \mathrm{V}$, and $\mathrm{Pb}$ were successfully determined and the concentration levels (in general) were in the order of decreasing abundance $\mathrm{V}$, $\mathrm{Pb}, \mathrm{Cr}$, Ni for RMINE, and $\mathrm{Cr}, \mathrm{V}, \mathrm{Pb}, \mathrm{Ni}$ for RCBD.

\section{Conclusions}

The concentrations of the metals identified at RCBD are generally lower than at RMINE. The average concentrations of Cr obtained at RMINE and RCBD were identified as $2.55( \pm 1.42)$ and $0.18( \pm 0.08) \mu \mathrm{gm}^{-3}$ for ICP-MS and $2.28( \pm 0.64)$ and 
$0.14( \pm 0.04) \mu \mathrm{gm}^{-3}$ for SEM/EDS. The relatively good agreement between the two techniques shows that the SEM/EDS technique is a suitable non-destructive characterisation tool. The ICP-MS and AAS concentrations for $\mathrm{Cr}, \mathrm{Ni}, \mathrm{V}$ and $\mathrm{Pb}$ are not comparable. The discrepancy in the ICP-MS and AAS determinations could not be explained thus further studies are needed.

The study has also shown that Scanning Electron Microscopy coupled with Energy Dispersive Spectrometry can be used as a tool to characterise particulate matter. The method however, could not yield all the required information on trace metals. The ability to perform non-destructive analysis of individual particles by SEM/EDS is indispensable in the characterisation of PM10 samples because it allows the same sample to be chemically speciated by other spectroscopic methods.

ICP-MS was shown to be a relevant characterization tool for particulate aerosols. The technique provides valuable information, which when properly analysed, can contribute significantly to studies on seasonal variations and source apportionment, and ultimately to exposure assessment studies. A large number of metals, both crustal and trace metals were identified using ICP-MS. It is suggested however, that determination of elemental composition of PM using ICP-MS for the purpose of identifying and quantifying major source contributions, be coupled with chemical speciation of ammonium, sulphate, nitrate, organic carbon, and elemental carbon. This is necessary because atmospheric particulate aerosols, in general, consist of sulphates, nitrates, seasalt, mineral dust, organics, carbonaceous components.

\section{Acknowledgements}

The authors acknowledge Dr L Tiedt and Mr P. Janse van Rensburg for the role they played in the analysis of filters. The financial support from the Finnish Environment Institute (SYKE) and the National Research Foundation (NRF) is greatly acknowledged.

\section{References}

[1] Dockery, D.W., Pope, C.A., Xu, X., Spengler, J.D., Ware, J.H., Fay, M.E., Ferris, B.G. \& Speizer, F.E. New England Journal of Medicine. 329, p. $1753,1993$.

[2] IPCC. The Third Assessment Report of Working Group I of the Intergovernmental Panel on Climate Change: Technical Summary, Lead Authors, Albritton DL (USA), Meira Filho LG (Brazil), Shanghai, pp. 1720, January 2001.

[3] McLaughlin, S.B. Effects of air pollution on forests: a critical review. Journal of the Air Pollution Control Association, 35 (5), pp. 512-534, 1985.

[4] Khlystov, A. Quality Assurance Project Plan for Pittsburgh Air Quality Study (PAQS), Department of Chemical Engineering, Carnegie Mellon University, 2001. 
[5] Goldstein, J., Newbury, D., Joy, D., Lyman, C., Echlin, P., Lifshin, E., Sawyer, L. \& Michael, J. Scanning Electron Microscopy and X-Ray Microanalysis, Third Edition, Kluwer Academic Publishers, New York, 2003.

[6] Li, X.Y., Gilmour, P.S., Donaldson, K. \& MacNee, W. Free radical activity and pro-inflammatory effects of particulate air pollution (PM10) in-vivo and in-vitro, Thorax, 51, pp. 1216-1222, 1996.

[7] Gilmour, P.S., Brown, D.M., Lindsay, T.G., Beswick, P.H., MacNee, W. \& Donaldson, K. Adverse health effects of PM10 particles: involvement of iron in generation of hydroxyl radical, Occupational Environment and Medicine. 53, pp. 817-822, 1996.

[8] Herbst, J.A. Control 84: Mineral/Metallurgical processing, American Institute of Mining, Metallurgical, and Petroleum Engineers, Inc. New York, 1984.

[9] Li, W-W., Bang, J.J., Chianelli, R.R., Yacaman, M.J., \& Ortiz, R. Characterization of Airborne Particulate Matter in the Paso del Norte Air Quality Basin, Morphology and Chemistry, 2000.

[10] Asia Pacific Centre For Environmental Law (APCEL), National University of Singapore, http://www.nus.edu.sg

[11] Buseck, P.R. \& Pósfai, M. Airborne minerals and related aerosol particles: effects on climate and the environment. Proc. of the National Academy of Sciences of the United States of America, 96, pp. 3372-3379, 1999.

[12] Zhang, D., Shi, G-Y., Iwasaka, Y. \& Hu, M. Mixture of sulfate and nitrate in coastal atmospheric aerosols: individual particle studies in Qingdao, Atmospheric Environment, 34, pp. 2669-2679, 2000.

[13] Pósfai, M., Simonics, R., Li, J., Hobbs, P.V. \& Buseck, P.R. Individual aerosol particles from biomass burning in southern Africa: Compositions and size distributions of carbonaceous particles. Journal of Geophysical Research-Atmospheres, 108, SAF 19/1-SAF 19/13, 2003.

[14] South African Weather Services (SAWS), http://www.saws.co.za

[15] Preston-Whyte, R.A. \& Tyson, P.D. The atmosphere and weather of Southern Africa, New York: Oxford University Press. Pp. 366, 1988.

[16] Ministry for the Environment and the Ministry of Health, Ambient Air Quality Guidelines, Air Quality Report No.32, New Zealand, ME number: 438, pp 9, May 2002. 